\title{
Elevator Regenerative Energy Applications with Ultracapacitor and Battery Energy Storage Systems in Complex Buildings
}

\author{
Mostafa Kermani ${ }^{1, *(D)}$, Erfan Shirdare ${ }^{2}$, Saram Abbasi ${ }^{2}$, Giuseppe Parise $^{2}$ and Luigi Martirano $^{2} \mathbb{D}$ \\ 1 Department Electrical Engineering, Chalmers University of Technology, SE-412 96 Gothenburg, Sweden \\ 2 Department of Astronautical, Electrical and Energy Engineering (DIAEE), Sapienza University of Rome, \\ 00184 Rome, Italy; shirdare@ieee.org (E.S.); saram.abbasi@ieee.org (S.A.); giuseppe.parise@uniroma1.it (G.P.); \\ luigi.martirano@uniroma1.it (L.M.) \\ * Correspondence: mostafa.kermani@chalmers.se
}

Citation: Kermani, M.; Shirdare, E.; Abbasi, S.; Parise, G.; Martirano, L. Elevator Regenerative Energy Applications with Ultracapacitor and Battery Energy Storage Systems in Complex Buildings. Energies 2021, 14, 3259. https://doi.org/10.3390/ en14113259

Academic Editor: Marc Medrano

Received: 4 April 2021

Accepted: 27 May 2021

Published: 2 June 2021

Publisher's Note: MDPI stays neutral with regard to jurisdictional claims in published maps and institutional affiliations.

Copyright: (c) 2021 by the authors. Licensee MDPI, Basel, Switzerland. This article is an open access article distributed under the terms and conditions of the Creative Commons Attribution (CC BY) license (https:// creativecommons.org/licenses/by/ $4.0 /)$.

\begin{abstract}
Due to the dramatic growth of the global population, building multi-story buildings has become a necessity, which strongly requires the installation of an elevator regardless of the type of building being built. This study focuses on households, which are the second-largest electricity consumers after the transportation sector. In residential buildings, elevators impose huge electricity costs because they are used by many consumers. The novelty of this paper is implementing a Hybrid Energy Storage System (HESS), including an ultracapacitor Energy Storage (UCES) and a Battery Energy Storage (BES) system, in order to reduce the amount of power and energy consumed by elevators in residential buildings. The control strategy of this study includes two main parts. In the first stage, an indirect field-oriented control strategy is implemented to provide new features and flexibility to the system and take benefit of the regenerative energy received from the elevator's motor. In the second stage, a novel control strategy is proposed to control the HESS efficiently. In this context, the HESS is only fed by regenerated power so the amount of energy stored in the UC can be used to reduce peak consumption. Meanwhile, the BES supplies common electrical loads in the building, e.g., washing machines, heating services (both boiler and heat pump), and lighting, which helps to achieve a nearly zero energy building.
\end{abstract}

Keywords: ultracapacitor; battery energy storage; elevator; peak shaving; regenerative energy; nearly zero energy building; hybrid energy storage system; cost analysis

\section{Introduction}

In this modern era, energy plays an undeniable role in different aspects of people's lives. Due to the growing rate of energy consumption, which imposes a huge cost to the electricity system, energy efficiency has become one of the main relevant fields in energy evaluation. Households constitute the second largest section of energy consumers [1]. Consequently, many studies have been conducted with the aim of achieving energy and cost-savings in buildings with different functions [2]. In this context, various control methods, such as the model-predictive method [3], demand response method [4], building management system [5], supervisory control and data acquisition system (SCADA) [6], and power-sharing model [7], have been investigated. As an effective solution, preventing the wasting of energy can help to achieve a nearly zero energy building and provide economic benefits [8]. Particularly in multistory buildings, elevators account for one of the main electricity demands at $3-10 \%$ based on the building type, such as residential, commercial, and industrial [9]. Unfortunately, this vertical transportation system has not been considered as a critical issue in terms of developing an efficient energy system for a long time. For instance, it has been customary to dissipate regenerative energy in the braking phase across an elevator's resistor bank. However, back-to-back converters enable using regenerative energy to effectively reduce the amount of required power. Hence, using regenerated energy can be effective for both energy consumption and peak power 
reduction. Hence, there are three main approaches for using regenerative energy that are displayed in Figure 1:

$>$ Case a: Dissipate regenerative energy in the resistor bank (conventional elevators).

$>$ Case b: Return the regenerated energy to the main grid through a backup converter.

$>$ Case c: Apply energy storage systems (ESSs) to utilize the regenerated energy for the elevator's motor operation or other issues.

(a)
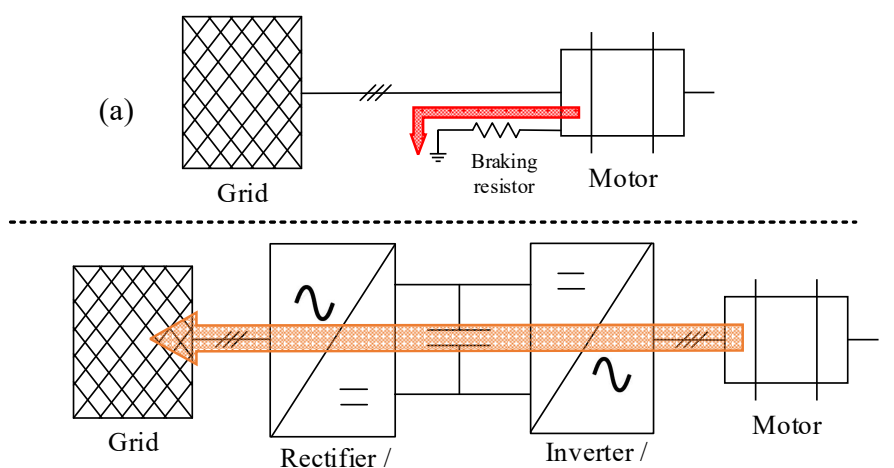

(b) Inverter

Rectifier

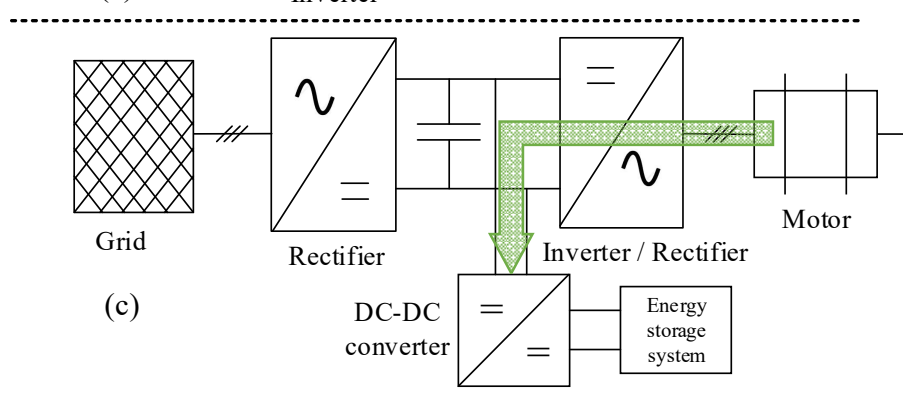

Figure 1. Main methods of using regenerative energy. (a) Waste on the resistor bank; (b) Send to the main grid; (c) Store in the energy storages.

As the most effective approaches, various solutions have been suggested to use regenerative energy (instead of wasting it) in elevator applications through the integration of ESSs. As an example, applying an ultracapacitor energy storage (UCES) with a control strategy to reduce its current ripple and consequently reach a higher energy saving level was investigated [10]. In [11], peak shaving and power smoothing in an elevator based on a high-efficiency power-converter topology was proposed. A comprehensive comparison between Flywheel Energy Storage (FES) and UCES is carried out in [12], the results of which show that the FES needs a higher initial cost and complex control strategy, while the UCES can be a convenient solution for this application because of a high lifetime, lower initial cost, and simple control strategy. As an interesting work, in addition to utilizing UCES and Battery Energy Storage (BES), a photovoltaic system as a second source (after the main grid) to have optimal and efficient energy management for an elevator system was applied [13]. The use of the elevator traffic flow model, with the aim of facilitating energy management and only implementing the UCES to increase the efficiency of elevators, was been published in [14] and [15], respectively.

An energy recovery system with improved power control and energy management capability based on UCES for elevator applications was investigated in [16]. The proposed system was connected to the DC link through a bidirectional DC/DC converter for storing and then recovering the regenerative energy.

Nevertheless, this paper evaluates the possibility of installing a Hybrid Energy Storage (HESS), including a BES and a UCES, with an elevator as the novelty of this paper that was not investigated before. The HESS is fed by only regenerative energy, which is obtained in the elevator's braking phase. The UCES is utilized for peak reduction and the amount 
of its input and output energy in each cycle is almost equal because of the equal charging and discharging rates in a cycle. That means during a full lifting cycle, the UCES State of Charge (SOC) for the starting and ending time will be same.

The UCES is connected to the DC link via an exclusive DC/DC bidirectional converter. Notably, the BES aims to save energy for common usage of the apartment's residents. The $\mathrm{BES}$ receives energy from the elevator in its regenerating mode through its DC/DC bidirectional converter and in long standby hours; for example during nighttime, it discharges to common appliances of the apartment, e.g., a washing machine, heating services (both boiler and heat pump), and lightings. It is noticeable that the BES has priority for energy receiving, and consequently, the UCES will charge only when the battery's charging current reaches a threshold value. Although cutting peak demand is not an issue especially in residential buildings, it can be an effective solution for an overall peak reduction from the main grid's point of view. As a result, the grid's authorities can consider some incentives or cost-based rules which lead residents to follow energy reduction approaches. As elevators are the largest consumers of energy in residential buildings, special attention should be paid to this issue.

\section{Elevator Operation}

Four torque-speed quadrants in an elevator are defined in Figure 2. According to the mechanical power of motor formula $\mathrm{P}=\mathrm{T} \cdot \omega$, when both amounts of torque and angular speed are positive or negative, the operating areas are called forward motoring and reverse motoring phases, respectively. Also, if the speed value is positive and the torque value is negative, the operating area is forward braking, while if the speed and the torque values are negative and positive, respectively, the desired area is called reverse braking. In the braking areas, the rotor speed exceeds the speed of the stator rotating magnetic field and the power flow direction is reversed compared to the motoring operation, flowing from the motor to the DC link, as a result, the motor acts as a generator. The use of regenerative energy in elevators is one of the main approaches to optimize energy consumption in large complexes, which significantly reduces their energy consumption [17]. An elevator operates in two modes involving four operating cycles of cabin vertical movements:

- $\quad$ Motoring mode: This means that the motor is applying force and torque to lift, which is the heavy side of the balance system (e.g., raising the full load cabin).

- Generating mode: For this mode, the motor does not generate positive torque, but the system shifts with its weight (e.g., lowering the full load cabin).

In conventional elevators (Figure 1a), when the elevator is in the generating mode, a relay detects the direction of current, so it is possible to determine when the braking resistor is connected to the circuit. This is useful because checking the braking resistor itself is not a suitable method, both from technical and economic points of view. Also, the method of sending excess power to the main grid requires the design and implementation of a backup converting system, thereby imposing a considerable cost to the grid system authorities, while the obtained benefits are not comparable to the initial investment. Hence, this study proposes a HESS to use a considerable proportion of regenerative energy in elevators.

Therefore, in this research, the goal was assigned to minimize the consumed energy in elevators. In the first step, the drive system of the electric machines with energy recovery capability was simulated in MATLAB Simulink. The simulation shows that by designing a suitable control system, a significant part of the regenerative energy can be stored via the ESS in the elevator's generating mode. The novelty of this paper is considering a HESS including a BES and a UCES. The control strategy applied in this paper operates in such a way that the amount of energy stored in the UCES will be used for peak load shaving in the motor and that of BES will be used for energy consumption reduction by supplying common load applications in the building. 


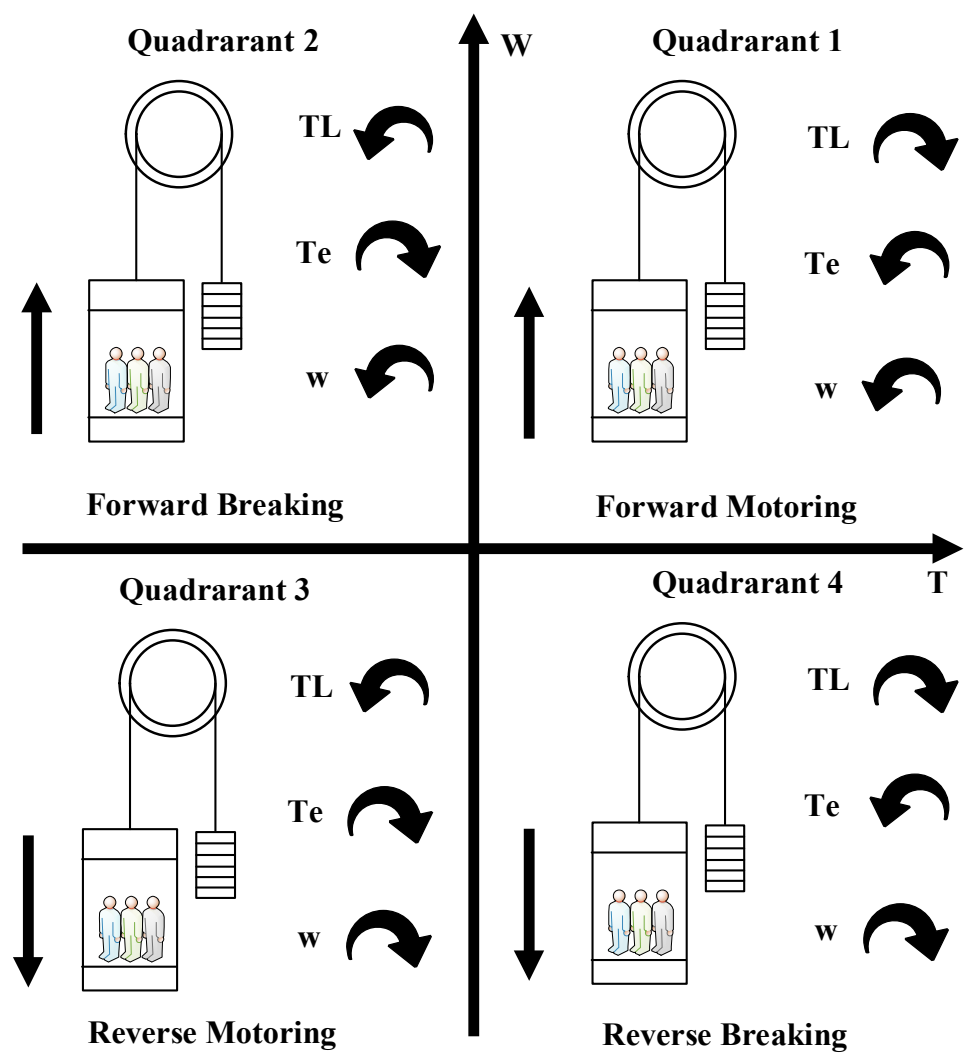

Figure 2. Operating quadrants of the elevator motor.

\section{Elevator Parameters Characteristics}

As is mentioned, the elevator is equipped with a back-to-back converter and as a result, it can use the benefits of regenerative energy to cut extra energy consumption. The selected elevator motor is a three-phase squirrel cage induction type that is connected to the traction sheave through the gearbox and then to the elevator cabin. The elevator characteristics are presented in Table 1.

Table 1. The characteristics of the elevator's motor.

\begin{tabular}{cccc}
\hline Parameters & Values & Parameters & Values \\
\hline Rated Power & $15 \mathrm{~kW}$ & Friction Factor & $0.01 \mathrm{~N} \cdot \mathrm{m} \cdot \mathrm{s}$ \\
Voltage & $380 \mathrm{~V}$ & Stator Resistance & $0.087 \Omega$ \\
Number of Phases & 3 & Rotor Resistance & $0.228 \Omega$ \\
Frequency & $60 \mathrm{~Hz}$ & Stator Inductance & $0.8 \mathrm{mH}$ \\
Number of Pole Pairs & 2 & Rotor Inductance & $0.8 \mathrm{mH}$ \\
Inertia & $1.662 \mathrm{Kg} \cdot \mathrm{m}^{2}$ & Mutual Inductance & $34.7 \mathrm{mH}$ \\
\hline
\end{tabular}

With the equation of motion, the behavior of acceleration, speed, torque, and power of the elevator motor in the four quadrants can be analyzed as follows in Equation (1).

In Equation (1), $T_{e}$ and $T_{L}$ represent the motor's electromagnetic torque and load torque, each. Also, $\omega$ is the angular speed, $a$ is the acceleration, and $P$ is the output power of the motor. Figure 3 illustrates the power, speed, and torque of the elevator motor that is simulated for a 45 -s cycle. During the complete 45-s cycle of the elevator, by considering the positive speed for moving the cab upwards and the negative speed for moving the cab downwards, in time intervals $A$ and $E$, the cab speed increases in the up and down directions, respectively. There are incremental variations in speed, resulting in a positive amount of acceleration. Additionally, the total torque during interval $A$ is positive and during interval $E$ is negative. The time intervals $A$ and $E$ are included in the accelerating speed phase. At time intervals $B$ and $F$, which are called the Steady-state phase, the speed 
of the cab reaches a constant value; thus, the speed changes and as a result, acceleration is equal to zero. The torque resultant at time intervals $B$ and $F$ is positive and the amount of electromagnetic torque becomes equal to the amount of load torque. Furthermore, during intervals $C$ and $G$, due to the applied braking torque, which is opposite to the direction of the speed, the cab speed decreases resulting in the negative values of the acceleration. In this case, the total torque at interval $C$ is negative and at interval $G$ is positive. These intervals are called the decelerating speed phase. Finally, during interval $D$, the cab is at a standstill, resulting in zero speed and acceleration values. That is why this interval phase is called the Stationary phase.

$$
T_{e}-T_{L}=j \frac{d \omega}{d t} \Rightarrow\left\{\begin{array}{c}
A) T_{e}>T_{L}(T>0), \frac{d \omega}{d t}=a>0, \omega>0 \Rightarrow P>0 \Rightarrow \text { Motoring phase } \\
\text { B) } T_{e}=T_{L}(T>0), \frac{d \omega}{d t}=a=0, \omega>0 \Rightarrow P>0 \Rightarrow \text { Motoring phase } \\
\text { C) } T_{e}<T_{L}(T<0), \frac{d \omega}{d t}=a<0, \omega>0 \Rightarrow P<0 \Rightarrow \text { Generating phase } \\
D) T_{e}=T_{L}(T>0), \frac{d \omega}{d t}=a=0, \omega=0 \Rightarrow P=0 \Rightarrow \text { Stationary phase } \\
E) T_{e}<T_{L}(T<0), \frac{d \omega}{d t}=a=0, \omega<0 \Rightarrow P>0 \Rightarrow \text { Motoring phase } \\
\text { F) } T_{e}=T_{L}(T>0), \frac{d \omega}{d t}=a=0, \omega<0 \Rightarrow P<0 \Rightarrow \text { Generating phase } \\
\text { G) } T_{e}>T_{L}(T>0), \frac{d \omega}{d t}=a<0, \omega<0 \Rightarrow P<0 \Rightarrow \text { Generating phase }
\end{array}\right.
$$

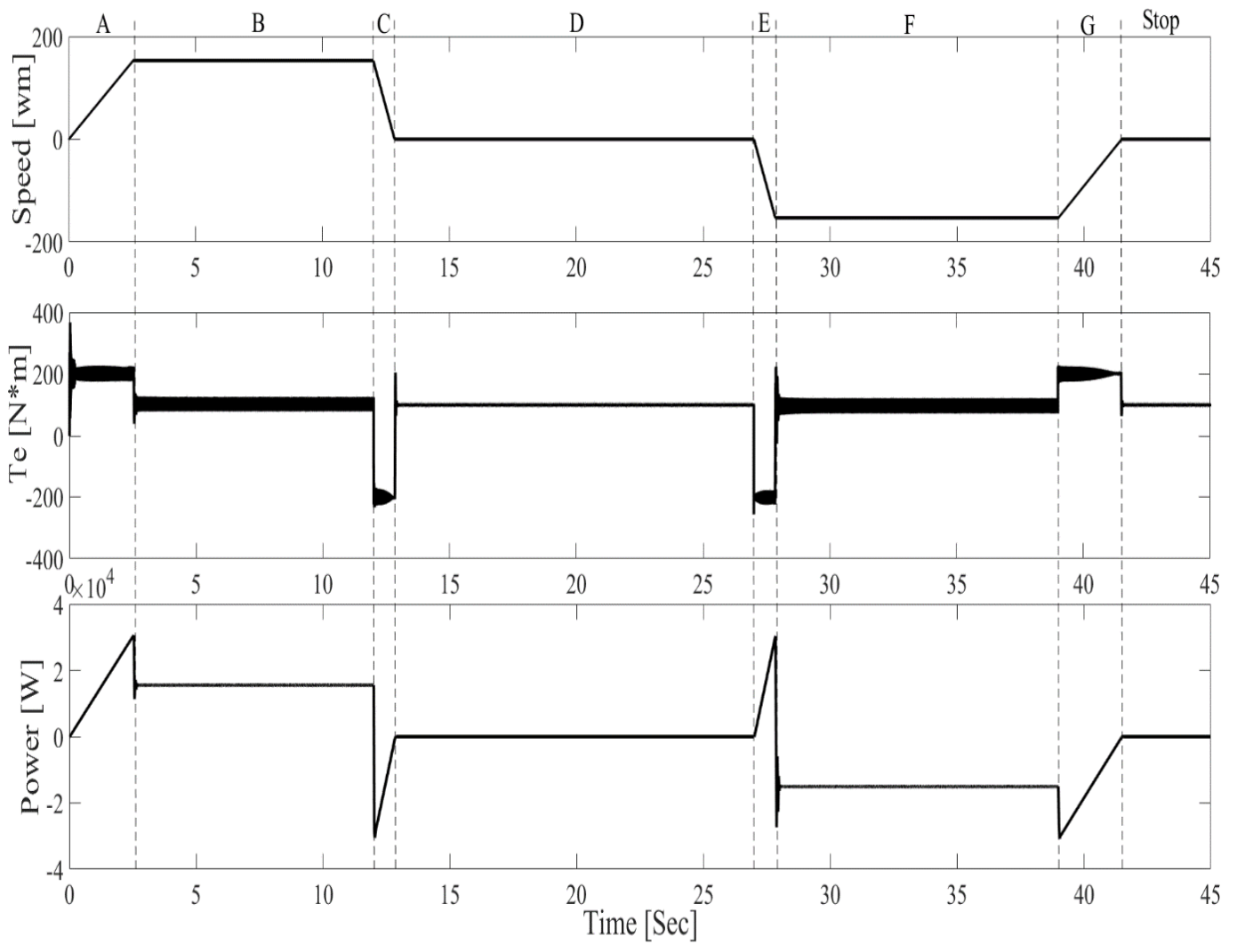

Figure 3. Simulated speed and torque power of the elevator motor.

Since there is a relationship between magnetic flux and torque in induction motors and they are interdependent, so with the change of torque, the magnetic flux will also change. Hence, it is not possible to control torque and speed independently. As a result, to separate the flux and torque equations, the vector method is used, which is the field-oriented control (FOC) method. The FOC controls the flux, torque, and speed of the motor. In FOC, unlike the scalar method, which deals only with the magnitude of the magnetic flux, it is also related to the angle of the field vector. Therefore, this control strategy is more accurate and reliable compared to the scalar method. 
The vector control includes FOC and direct torque control methods. In this paper, the FOC with the indirect type method was used to control the induction motor of the elevator. It should be noted that the indirect field-oriented control (IFOC) method is the optimal method that is very efficient especially for high power motors, and due to the separation of currents on the $d-q$ axes that leads to a reduction in losses and energy consumption, while in the scalar approaches, if the amplitude of the current increases, the $i_{d s}$ increases proportionally with $i_{q s}$, which since $i_{d s}$ does not play a role in producing torque, causes a large quantity of losses. Hence, the IFOC is the adequate control strategy for the proposed system.

The basis of the FOC is based on the equations of voltage and linkage flux of stator and rotor on the $d$ and q axes, while Equations (2) and (3) are obtained by Park transform:

$$
\begin{gathered}
\text { Stator Equations : }\left\{\begin{array}{c}
V_{d s}=R_{s} i_{d s}+D \lambda_{d s}-\omega \lambda \lambda_{q s} \\
\lambda_{d s}=L_{l s} i_{d s}+L_{m}\left(i_{d s}+i_{d r}\right) \\
V_{q s}=R_{s} i_{q s}+D \lambda_{q s}+\omega \lambda_{d s} \\
\lambda_{q s}=L_{l s} i_{q s}+L_{m}\left(i_{q s}+i_{q r}\right)
\end{array}\right. \\
\text { Rotor Equations : }\left\{\begin{array}{c}
V_{d r}=R_{r} i_{d r}+D \lambda_{d r}-\left(\omega-\omega_{r}\right) \lambda_{q r} \\
\lambda_{d r}=L_{l r} i_{d r}+L_{m}\left(i_{d s}+i_{d r}\right) \\
V_{q r}=R_{r} i_{q r}+D \lambda_{q r}-\left(\omega-\omega_{r}\right) \lambda_{d r} \\
\lambda_{q r}=L_{l r} i_{q r}+L_{m}\left(i_{q s}+i_{q r}\right)
\end{array}\right.
\end{gathered}
$$

Equations (2) and (3) show the voltage and flux linkages relations of the stator and rotor on the d-q axes. Moreover, parameters $R_{s}$ and $R_{r}$ are ohmic resistances of the stator and rotor windings each. Also, $i_{d s}$ and $i_{q s}$ are currents passing through the stator winding corresponding to axis $\mathrm{d}$ and $\mathrm{q}$, and $D$ is the derivative operator. Similarly, $i_{d r}$ and $i_{q r}$ are currents passing through the rotor winding corresponding to axis $\mathrm{d}$ and $\mathrm{q}$, and $\omega$ is the angular speed of the stator. The $\omega_{r}$ is the angular speed of the rotor, $\lambda_{d s}$ and $\lambda_{q s}$ are flux linkages of the stator on d-q axes, and $\lambda_{d r}$ and $\lambda_{q r}$ are flux linkages of the rotor on d-q axes. Finally, $L_{m}$ represents magnetizing inductance, and $L_{l s}$ and $L_{l r}$ are leakage inductances of the stator and rotor, respectively. The FOC conditions, assuming rotor field control and $\lambda_{q r}=0$, are as follow:

1. Supply the motor with frequency $\omega$, based on Equations (2) and (3) following the formula: $\omega=\omega_{r}+\left(R_{r} L_{m} / L_{r}\right) \cdot\left(i_{q s} / \lambda_{d r}\right)$.

2. If $\lambda_{q r}=0$ then $\lambda=\lambda_{d r}$, which must be kept constant by the control system so that the changes in magnetic flux are zero.

In FOC, $i_{d s}$ is the magnetic flux generating current and $\mathrm{i}_{\mathrm{qs}}$ is the torque generating current, as well as $\theta_{f}$ which is the angle of the rotor magnetic field. Equation (4) was used to implement the indirect (IFOC) [18] in which the $\theta_{f}$ is obtained by $\omega_{r}$. In Equation (4), $T_{e}{ }^{*}$ is an electromagnetic torque reference, $\omega_{s l}{ }^{*}$ is the angular speed of slip, and $\theta$ is the angular position and both $\tau_{r}$ and $K_{T}$ are constant values.

$$
\begin{aligned}
& i_{d s}{ }^{*}=1+D \tau_{r} \lambda_{d r}{ }^{*} / L_{m} \\
& i_{q s}{ }^{*}=\left(1 / k_{T} \lambda_{d r}{ }^{*}\right) \cdot T_{e}{ }^{*} \\
& T_{e}{ }^{*}=k_{T} \lambda_{d r}{ }^{*} i_{q s}{ }^{*} \\
& \omega_{s l}{ }^{*}=\left(L_{m} / \tau_{r} \cdot \lambda_{d r}{ }^{*}\right) \cdot i_{q s}{ }^{*} \\
& \theta_{f}=\theta_{r}+\theta_{s l}=\int\left(\omega_{r}+\omega_{s l}\right) d t \\
& \tau_{r}=L_{r} R_{r} \\
& D \theta=\omega \\
& \theta=\omega t+\theta_{0}
\end{aligned}
$$




\section{ESSs Selection for Elevators}

Nowadays, maintaining a power and energy balance [19], load leveling, and peak shaving [20] are huge challenges in power systems that the ESSs can deal with [21]. A comparison of the main ones such as UCES, BES, and FES is shown in Figure 4. As a general classification, the BESs are widely used for energy management applications (due to their high energy density), while the UCES and FES are suitable for peak shaving purposes because of their high power density [22]. As a comprehensive study, the applications of UCES [23], FES [24], and BES [25] were summarized in detail. In this paper, because of the existing peak powers and a noticeable amount of regenerative energy, a HESS based on UCES and BES was proposed. The most critical applications of UCESs are for peak shaving issues such as controlled electric drives [26], port cranes [27], hybrid excavator machines [28], and traction drives [29], while the BESs are usually used for energy management along with renewable energy sources [30-32], microgrids [33-35], and electric vehicles [36].

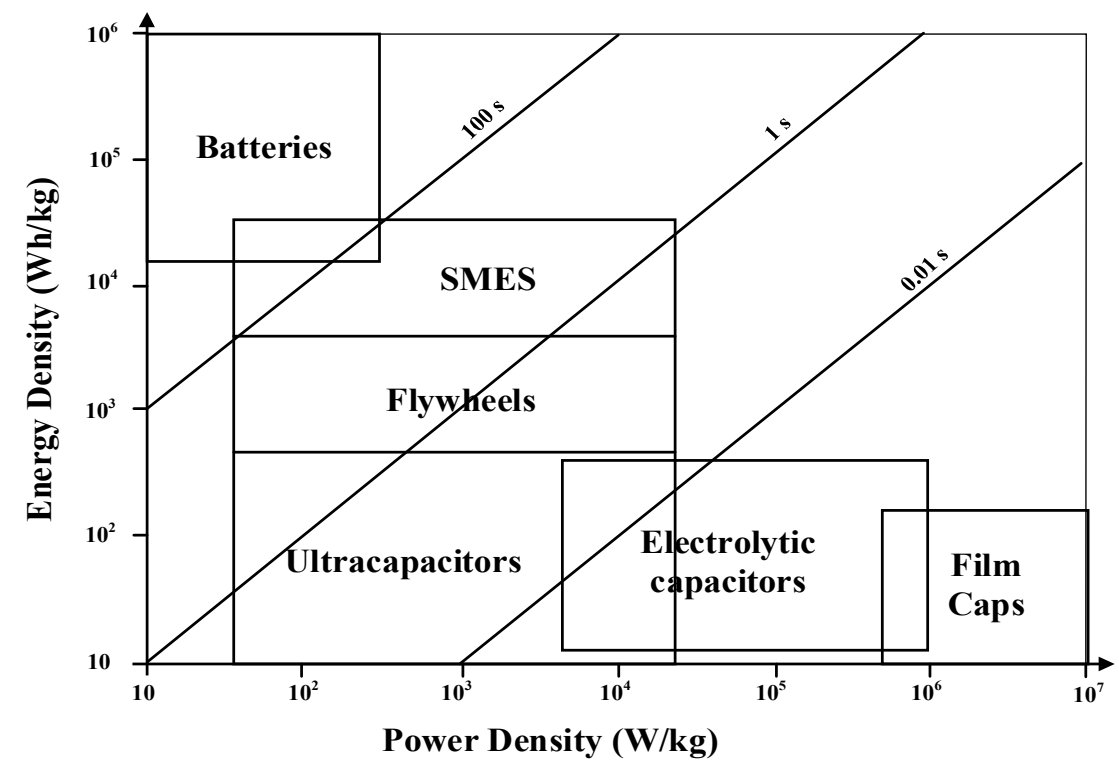

Figure 4. Comparison of power and energy densities of different energy storage technologies.

\section{Control Strategies for the Case Study}

Figure 5 shows the overall layout of a traction elevator, which consists of three main parts. First, the main grid is connected to a DC link through a three-phase rectifier. Then the HESS including BES and UCES is installed in the DC link by two exclusive bidirectional DC/DC converter as the second part. UCES exchanges power with the DC-link during both charging and discharging modes, while BESS receives the regenerative energy from the DC link (charging mode) and transfers it to the common loads (discharging mode). The motor is controlled by the IFOC strategy which is investigated in Section 5.1. 


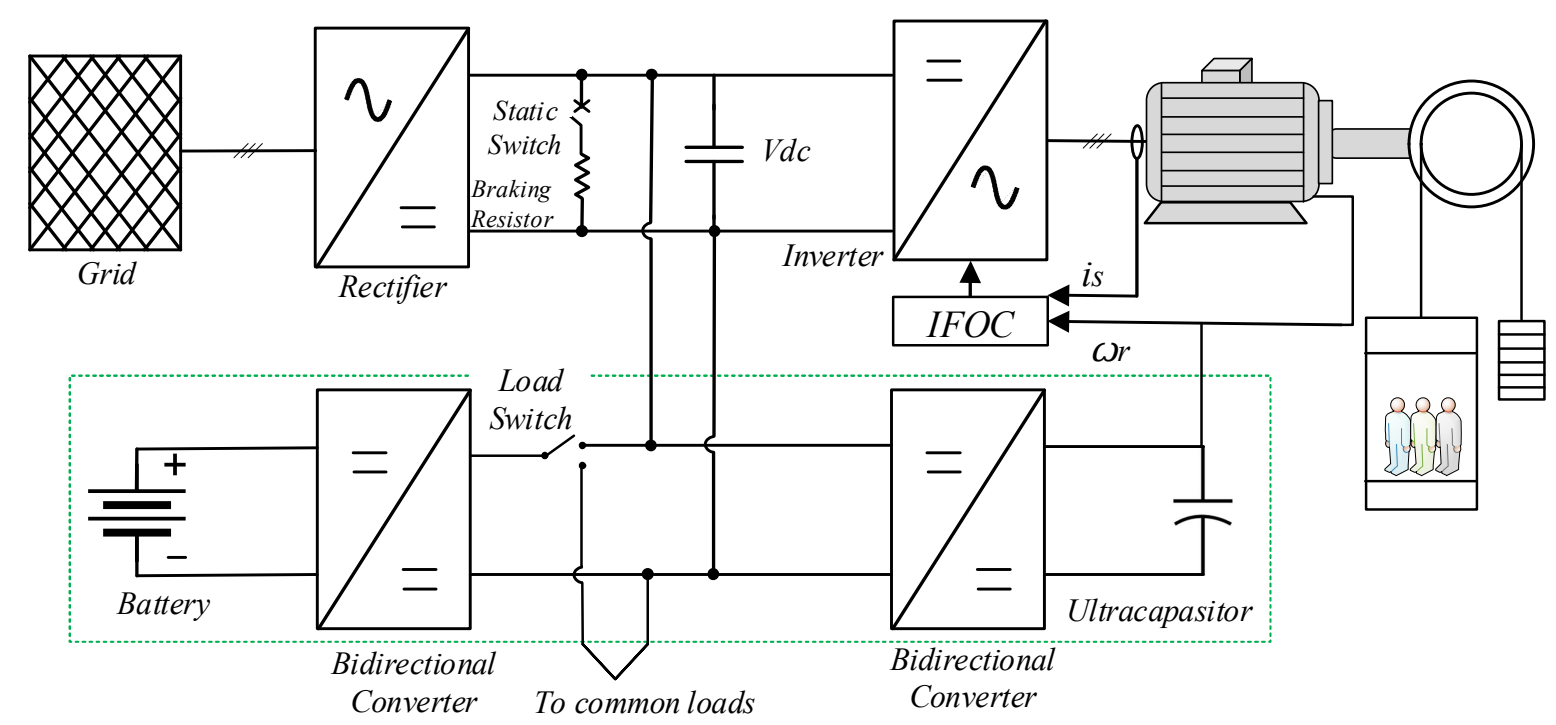

Figure 5. The overall configuration of the elevator is equipped with HESS and bidirectional converters.

\subsection{IFOC Strategy}

Figure 6 reveals the block diagram of the IFOC. As is clear, the mechanical rotor speed, $\omega_{\mathrm{r}}$, was added by slip speed, $\omega_{s l}$, which produced $\omega_{s}$. The integration of $\omega_{s}$ by PI control block resulted in the field angle $\theta_{f}$. Besides, the references $i_{d s}$ and $i_{q s}$ were generated by the reference torque $T_{e}{ }^{*}$ and flux linkage $\lambda_{\mathrm{r}}{ }^{*}$ using the relevant formulas in Equation (4), which were compared with their actual values obtained from the Park transform block(abc/dq) to produce the error values. The errors were then processed by the PI blocks or current controllers to provide the stator reference voltages on the d-q axes $\left(V_{d s}{ }^{*}\right.$ and $\left.V_{q s}{ }^{*}\right)$. Finally, the reference voltages and the field angle $\theta_{f}$ were given to the input of the inverse Park transform block (dq/abc), then the output was given to the PWM block to generate an inverter gating signal.

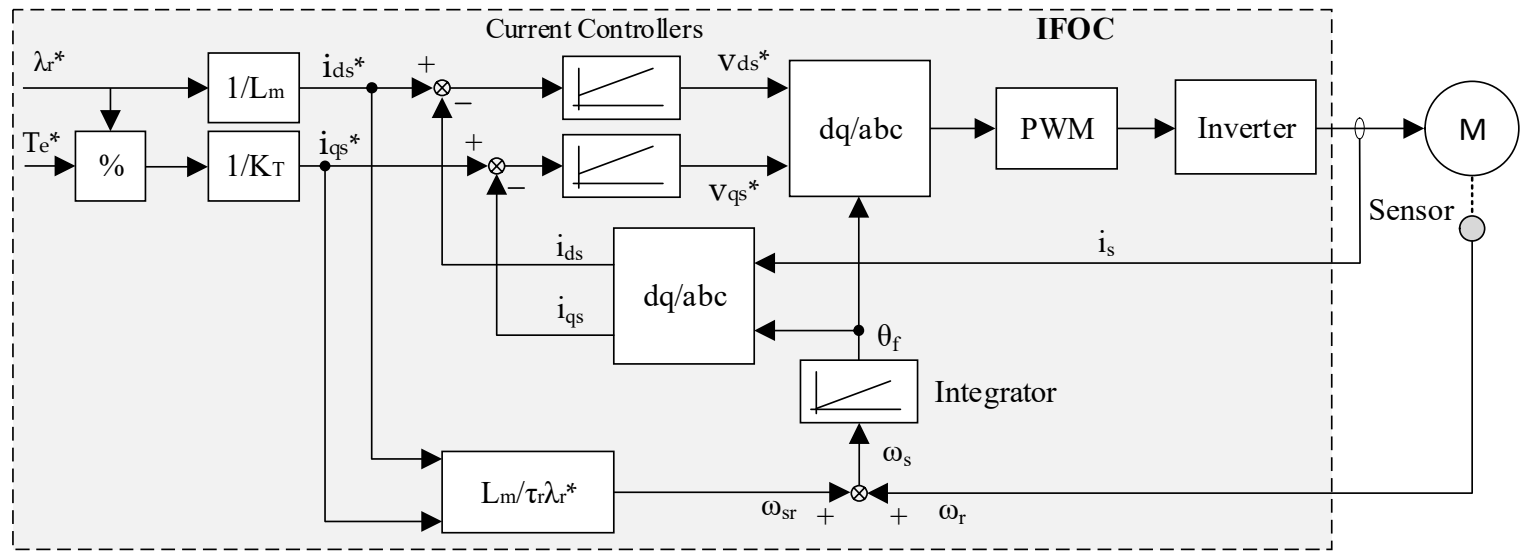

Figure 6. The IFOC in the induction motor.

\subsection{HESS Control Strategy}

It is possible to manage power-sharing between ESSs and DC link by controlling the $\mathrm{DC} / \mathrm{DC}$ converters. The BES is responsible for controlling the DC link voltage, while UCES supervises the output current according to the BES output current. As is shown, the UCES has two control strategy loops. The inner loop deals with fast responses, and the outer loop creates a reference value for the inner control loop. Based on Figure 7, the control strategy can work in three different conditions. 
- Mode A: According to Figure 7a, when the system is faced with a high load demand, the BES is the first ESS to discharge. UCES will discharge if the BES current reaches a threshold current $\left(\mathrm{I}_{\mathrm{BES}, \text { th1 }}\right)$. However, in charging mode, which happens in the case of a low load demand, both ESSs charge together and at the same time. UCES charging current was dynamically obtained according to BES charging current.

- Mode B: As is shown in Figure 7b, both UCES and BES discharge at the same time in the case of high-power demand. Nevertheless, the BES receives its charge first and when its charging current reaches another threshold ( $\mathrm{I}_{\mathrm{BES}}$, th2), the UCES begins to charge. Again, the UC current was determined based on the BES current (see Figure 8).

- $\quad$ Mode C: Based on Figure 7c, this mode is composed of modes A and B. When the load demand is high, the BES discharges first, and UCES discharges after the BES discharging current reaches $\mathrm{I}_{\mathrm{BES}, \text { th1. }}$. On the opposite side, in the case of low load demand, the BES is charged first and the UCES starts to charge when the BES charging current reaches $\mathrm{I}_{\mathrm{BES} \text {, th2 }}$.

As a result, this paper proposes a different control strategy for the HESS. As is shown in Figure 8, the suggested control strategy acts in such a way that BES discharges to the building's common load instead of the elevator.

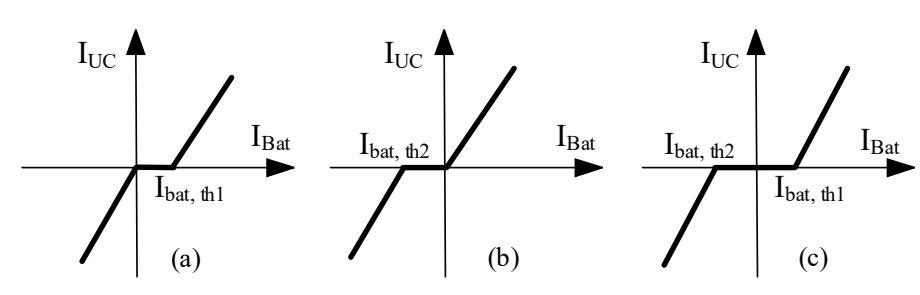

Figure 7. Three conventional control strategies cover different control situations [37]. (a) BES priority in discharging; (b) BES priority in charging; (c) BESS priority in both charging and discharging.

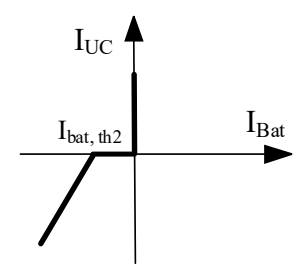

Figure 8. The proposed control strategy for HESS.

\subsubsection{BES Control Strategy}

Figure 9 illustrates the control strategy applied to ESSs. The BES in this paper was used to store the regenerative energy of the elevator. In this case, the BES absorbed a part of the regenerative energy to supply the common loads of the building during the discharging time. In Figure $9 \mathrm{a}$, the DC link voltage reference value is compared with its measured value in the first stage. The battery reference current was obtained by applying a PI controller to the collected error value of the previous step. Next, a comparison between the battery reference current and measured current was accomplished. The error value passes through another PI controller for generating the appropriate signals for switches utilizing PWM.

\subsubsection{UCES Control Strategy}

As mentioned before, during the motor mode of the elevator, the UCES is discharged for peak shaving. The UCES starts to charge after the BES charging current reaches a threshold to consider the battery's priority in receiving regenerative energy, as shown in Figure $9 \mathrm{~b}$. On the opposite side, the UC operates without considering the BES current and immediately starts to discharge in the case of high load demand. Hence, the reference value of the UC current is created by a comparison of the BES current and control strategy of HESS, which is shown in Figure 8. This current is subtracted from the actual current 
to build the UC's current error. To eliminate the error, this current is processed in the PI controller to optimally prepare the waveform for comparison with the PWM signal carrier. The output signal of this block is then compared with the PWM signal to generate gate control pulses.

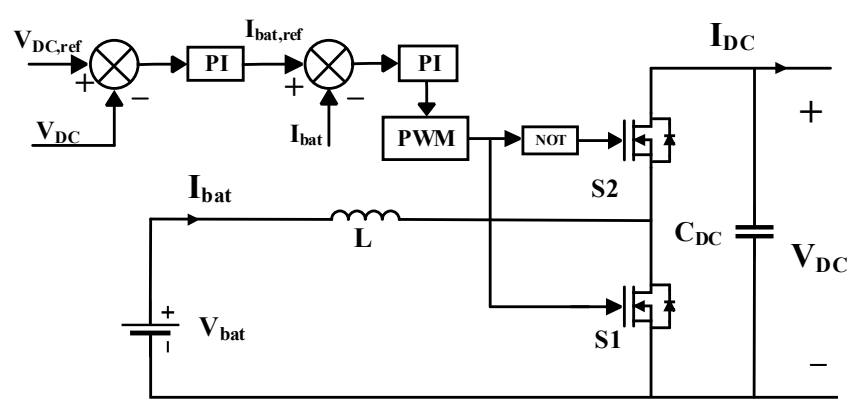

(a)

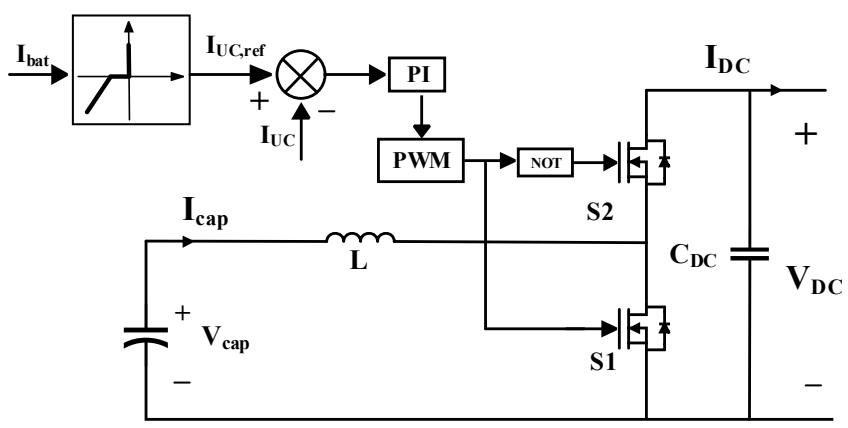

(b)

Figure 9. HESS control strategy. (a) BES Charging/Discharging; (b) UCES Charging/Discharging.

\subsection{Braking Chopper Control Strategy}

The braking chopper, which includes a braking resistor, static switch, and a simple control system, was designed to control the DC link voltage in the case of any emergency conditions. Based on Figure 10, if the state of charge (SOC) of both BES and UCES is more than $95 \%$, then a logic value of 1 is generated for the output, which turns the switch to on and results in the connection of the braking resistor to the circuit. Therefore, this extra energy is wasted in the form of heat across the resistor.

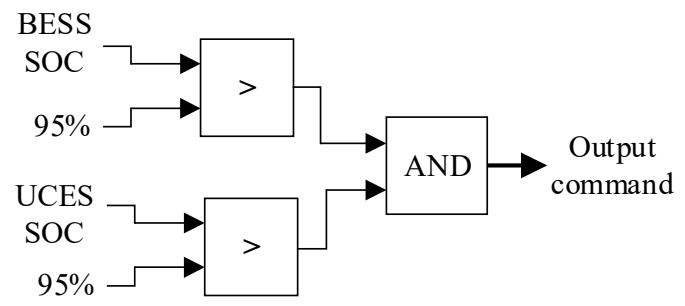

Figure 10. Braking chopper control strategy.

\section{UCES and BES Sizing and Cost Evaluation}

In this paper, a HESS including UCES to accomplish peak shaving and BES for energysaving purposes was considered based on regenerative energy utilization by obtaining the size of both BES and UCES [38,39]. Various studies investigated the size of ESSs in different systems. Due to the load profile of an elevator, the main grid experiences a huge amount of peak power for just a few seconds, which can be eliminated by the implementation of UCES. To avoid charging from the main grid, the UCES receives power from regenerated power created by the motor. As is presented in Figure 3 (the load profile), the UCES provides power in time intervals $\mathrm{A}$ and $\mathrm{E}$, and to return the consumed energy of each part, the regenerated energy charges the UCES in intervals C and G. The BES is assigned to store regenerative energy of interval $\mathrm{F}$ to supply common loads in the building, e.g., washing machines, heating services (both boiler and heat pump), and lighting. According to the peak power of regenerative energy, the BES must be able to receive $15 \mathrm{~kW}$ power in charging mode. According to the area of interval F, the amount of each cycle can be calculated as follows. The BES receives $56.9 \mathrm{Wh}$ in each cycle. Since the number of 
elevator's daily cycle is assumed as 250 times, the required size of the BES can be obtained as follows. Consequently, the BES size must be approximately $15 \mathrm{kWh}$.

$$
\text { Total Daily Energy } \Rightarrow E=\underbrace{56.9}_{\text {Wh per cycle }} \times \underbrace{250}_{\text {cycles per day }}=14,225 \mathrm{Wh} / \text { day }
$$

Similarly, the UCES must be able to store 4 Wh in each cycle, but it does not need to store this 250 times because it will discharge entirely in the next cycle. As a result, the capacity of UCES must be higher than $4 \mathrm{Wh}$. In addition to the sizing of the ESSs, both must be able to receive and produce $15 \mathrm{~kW}$ of power to cover the peak power of regenerated power in the regenerative phase.

As this paper aimed to reduce the total cost of the system, it would not be fair to only consider the earnings that the HESS provides; instead, the initial costs related to buying new equipment, such as BESs, UCESs, and DC/DC converters, must be included too. According to the sizing section and the fact that both ESSs must have a rated power of $15 \mathrm{~kW}$, a BYD BATTERY-BOX PREMIUM BES [40], and a GEN 31-0900-12V-2T [41] UC modules are required. The battery and UC module constitute BES and UCES, respectively. The energy storage specifications are shown in Table 2.

Table 2. Specification of the ESSs.

\begin{tabular}{cccc}
\hline $\begin{array}{c}\text { Energy Storage } \\
\text { Type }\end{array}$ & $\begin{array}{c}\text { Nominal Voltage } \\
(\mathbf{V})\end{array}$ & $\begin{array}{c}\text { Maximum Power } \\
(\mathbf{k W})\end{array}$ & $\begin{array}{c}\text { Nominal Capacity } \\
(\mathbf{W h})\end{array}$ \\
\hline BES & 51 & 15.36 & 15,400 \\
UCES & $7.2-16.2$ & 16.4 & 18.2 \\
\hline
\end{tabular}

Each energy storage is connected to the DC link through its exclusive bidirectional DC/DC converter. The price of the BES, UC module, and DC/DC converter are EUR 6000, 410, and 500, respectively. Finally, the initial investment of the system will be obtained as almost EUR 7410. Table 3 provides information regarding the total energy saving obtained by using the HESS. The number of daily cycles of the elevator was considered 250 times.

Table 3. The amount of daily stored energy and earning profits of each ESS.

\begin{tabular}{ccc}
\hline Energy Storage Type & $\begin{array}{c}\text { Stored Energy by } \\
\text { the ESS (Wh) }\end{array}$ & $\begin{array}{c}\text { Annual Earning Profit } \\
\text { (EUR) }\end{array}$ \\
\hline BES & 14,223 & 1297.7 \\
UCES & 1000 & 91.3 \\
HESS & 15,223 & 1389 \\
\hline
\end{tabular}

The payback was calculated by dividing the initial cost by annual profit so that the initial investment could be returned to the owners before the middle of the sixth year (as shown in Figure 11). The lifetime of each component can be obtained in Table 4 (The nominal life cycles of devices are driven from their datasheet).

Table 4. Lifetime calculation based on the life cycle and the daily cycle of each ESS.

\begin{tabular}{cccc}
\hline Energy Storage Type & Life Cycles & $\begin{array}{c}\text { No. of Cycles } \\
\text { per Day }\end{array}$ & $\begin{array}{c}\text { Lifetime } \\
\text { (Years) }\end{array}$ \\
\hline BES & 5000 & 1 & 14 \\
UCES & 500,000 & 65 & 21 \\
DC/DC converter & 30 years & 70 & 30 \\
\hline
\end{tabular}




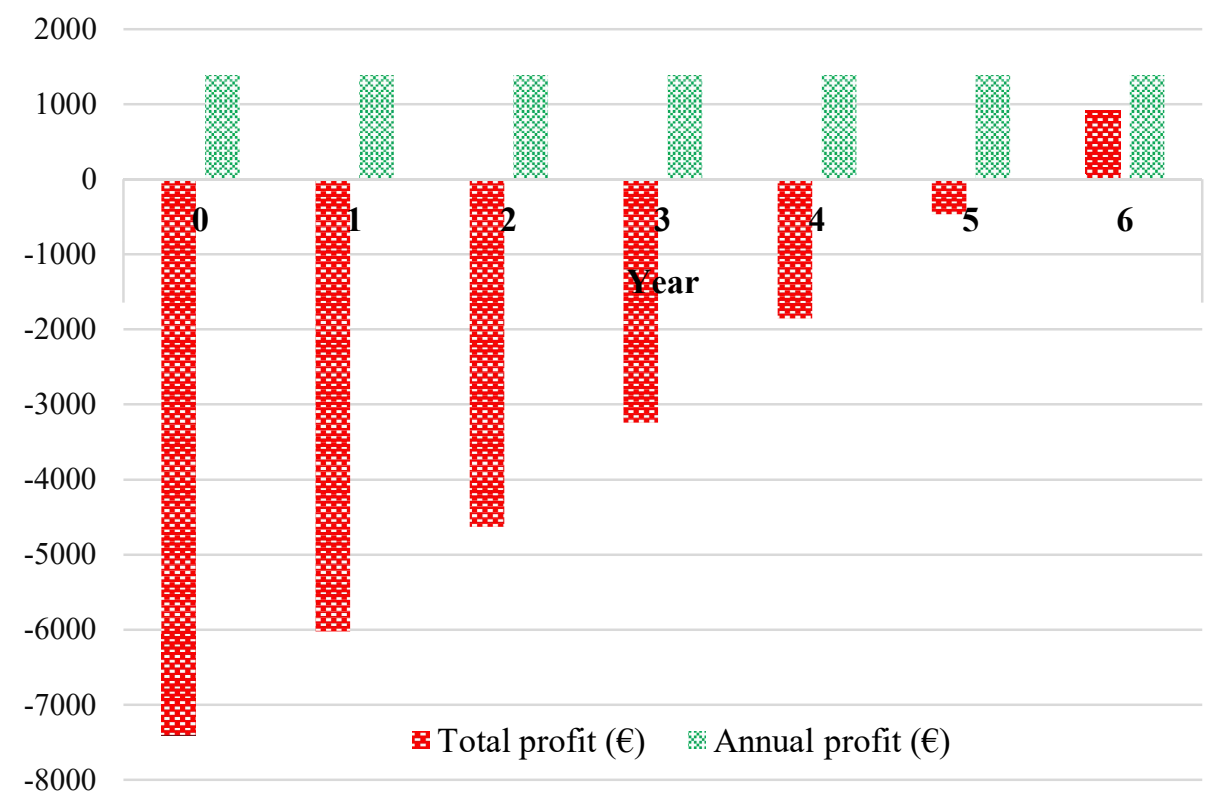

Figure 11. The total and annual earned profits.

\section{Results}

Figures 12 and 13 show the voltage, current, SOC, electrical power of the UCES, and the BES in a complete 45-s elevator working cycle, respectively. Besides, Figure 14 compares the electrical power of the elevator motor, main grid, UCES, and BES during the cycle. As is shown in Figure 12, UCES's import and export energy is equal and as a result, UCES does not receive energy from the main grid and it provides energy for extreme power peaks that happen in the dropping process. On the opposite point, BES's receiving and sending points are different, as was completely discussed before. In this context, Figure 13 reveals that BES is charged at a rate of $15 \mathrm{~kW}$ in the dropping process in order to supply the common loads.

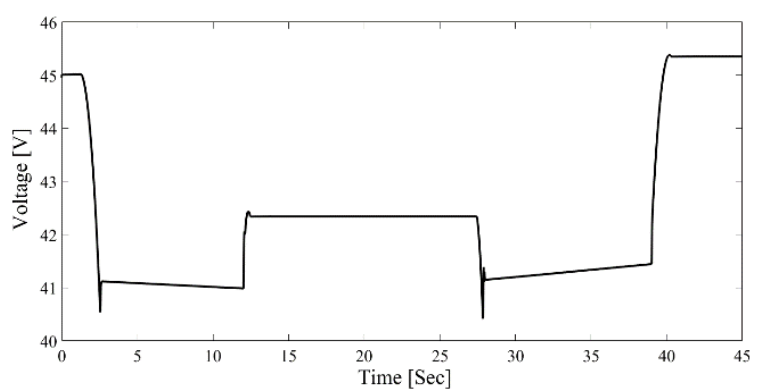

(a) UCES Voltage

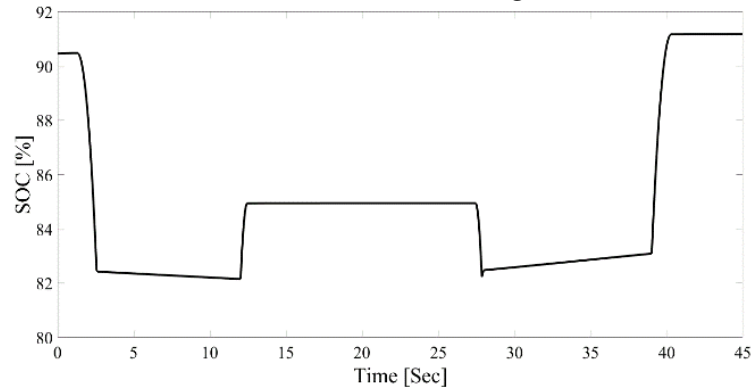

(c) UCES SOC

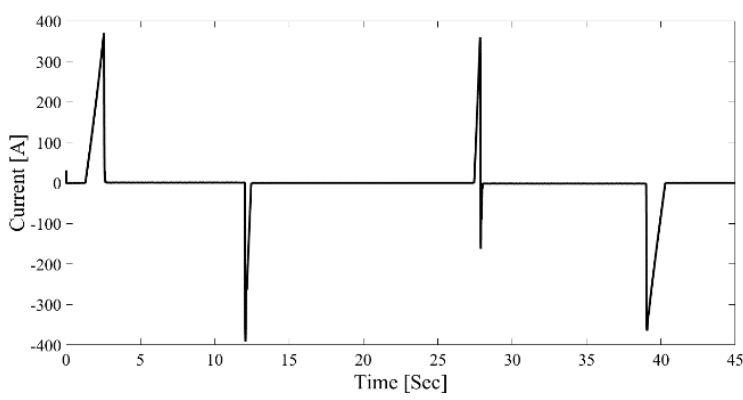

(b) UCES Current

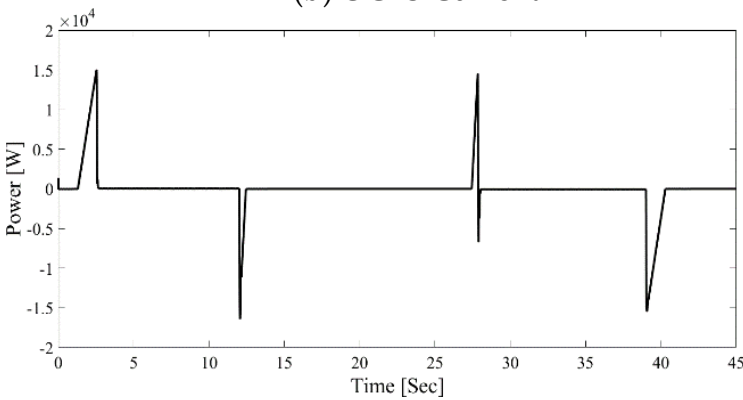

(d) UCES Power

Figure 12. UCES parameters in a complete 45-s elevator working cycle. 


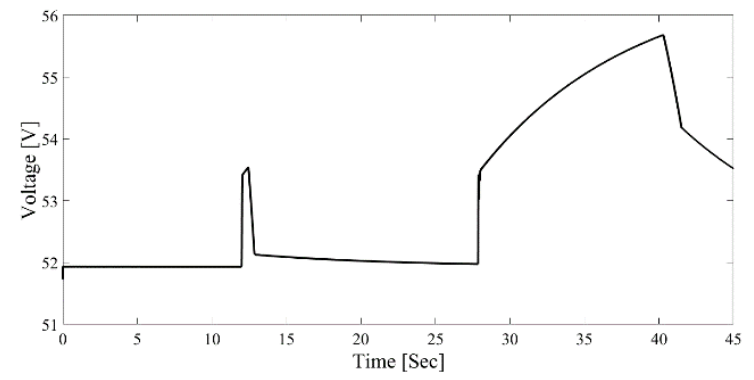

(a) BES Voltage

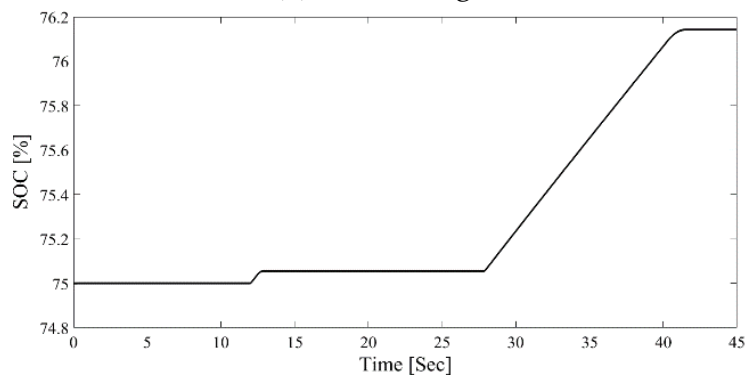

(c) BES SOC

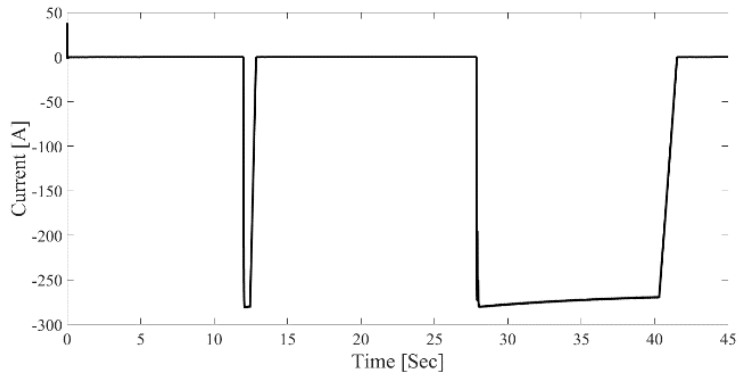

(b) BES Current

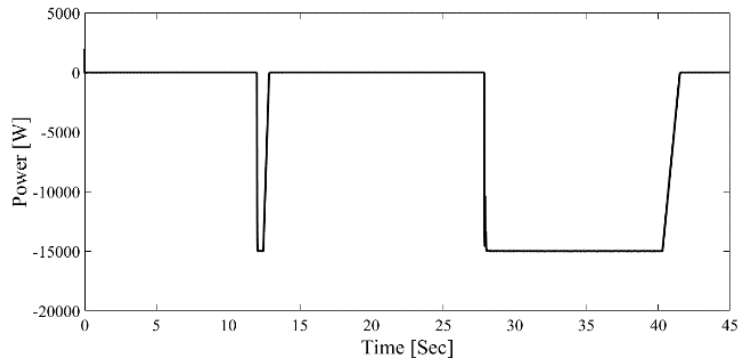

(d) BES Power

Figure 13. UCES parameters in complete 45-s elevator working cycle.

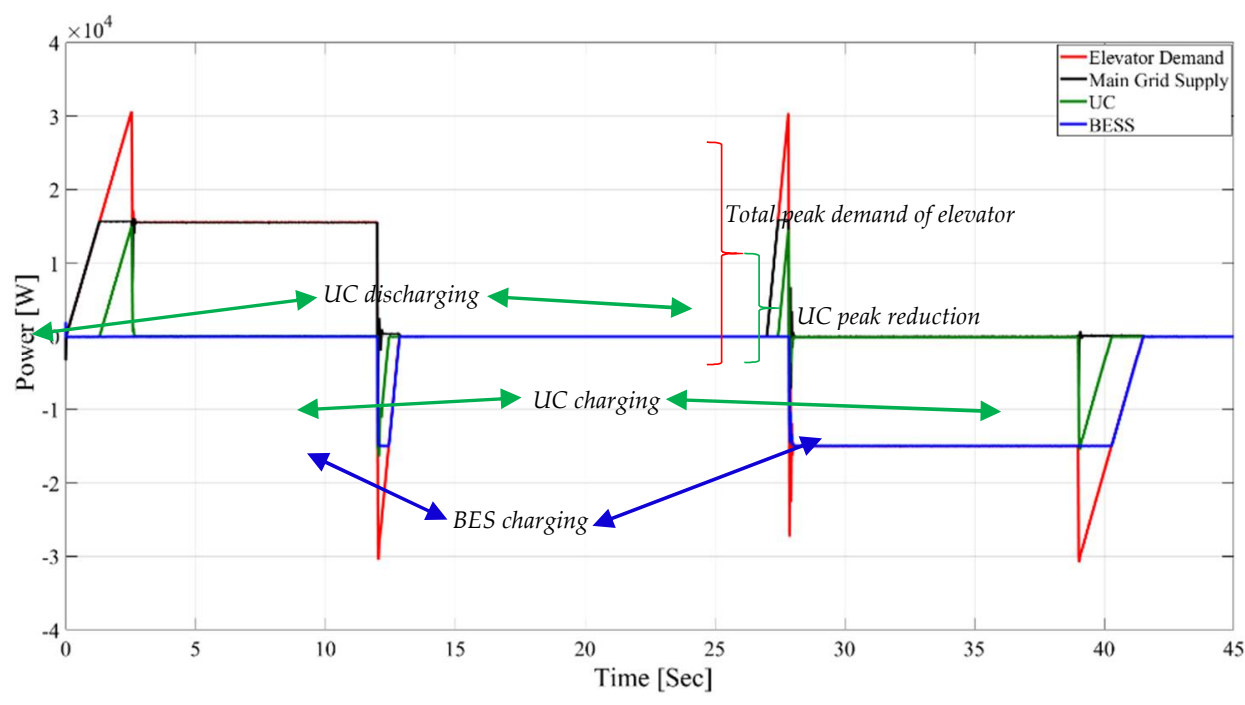

Figure 14. Elevator power supply provided by UCES, BES, and the main grid.

For both ESSs, the rate of voltage and current is proportional to the SOC and electric power. According to Figure 12, when the elevator operates in the motoring phase, the voltage and SOC of the UCES are reduced considerably, and in the steady-state phase, the slope of the reduction is lower. In other words, the UCES is discharged and acts parallel to the main grid to deliver power to the DC microgrid for peak-shaving. On the other hand, in the generating mode, these two values increase, which indicates that UCES is charged by the regenerative energy in the deceleration mode. In addition to these two mentioned states, the parameters remain constant in the stationary phase.

As electric power and current are proportional to each other, the changes of these values in comparison with the voltage and SOC occur in a shorter period. In the motoring mode, by discharging the UCES, the negative current and power values result in energy transfer from the DC link to the UCES.

Regarding BES behavior, as shown in Figure 13, like the UCES, the voltage is proportional to the SOC and the current is proportional to the electric power, such that in the motoring and steady-state phases, all of the above values are constant, while in the 
generating mode, voltage values and SOC of BES increase and currents and electrical power decreases, which indicates the BES charge caused by the regenerative energy.

Figure 14 illustrates that in the motoring mode (between 0 and $12 \mathrm{~s}$ ), the main grid electrically supplies the elevator's motor. The UCES operates parallel to the main network and discharges to help the peak shaving and the BES power does not participate in this section. This peak shaving is not a cost-effective issue in residential buildings; however, it is considered as one of the most important issues in industrial buildings, Nevertheless, in the braking mode (from 27 to $42 \mathrm{~s}$ ), the elevator is in generating mode, which demonstrates that the BES is charging by receiving regenerative energy. Finally, the UCES is absorbing power from 38 to $42 \mathrm{~s}$ to compensate for the amount that it discharges during the lifting process (27 to $28 \mathrm{~s}$ ). In the stationary phase, all the values are equal to zero.

\section{Conclusions}

In this paper, a hybrid energy storage system (HESS) including battery energy storage (BES) and ultracapacitor energy storage (UCES) has been proposed in order to use the regenerative energy from elevators to get closer to achieving a nearly zero energy building. The suggested method includes two main controlling parts, an elevator motor, and hybrid energy storage control systems. The indirect field-oriented control strategy for the elevator motor was used to take the advantage of decreasing the energy consumption of the system. Also, the special proposed control strategy of the hybrid energy storage system acted in such a way that the stored energy into the UCES and BES was used for the peak shaving of the building's common loads, respectively. According to performed comprehensive economic analysis, the BES and UCES released almost $14.2 \mathrm{kWh}$ and $1 \mathrm{kWh}$ energy per day, respectively. Consequently, the HESS caused a cost reduction of about EUR 1400 in a year and the initial investment could be returned during the sixth year.

Author Contributions: Investigation, review, and editing, M.K.; writing, and editing, E.S. and S.A.; editing and project administration, G.P. and L.M. All authors have read and agreed to the published version of the manuscript.

Funding: This research received no external funding.

Institutional Review Board Statement: Not applicable.

Informed Consent Statement: Not applicable.

Data Availability Statement: The data is available upon request.

Conflicts of Interest: The authors declare no conflict of interest.

$\begin{array}{ll}\text { Abbreviations } \\ \text { BES } & \text { Battery Energy Storage } \\ \text { FOC } & \text { Field Oriented Control } \\ \text { FES } & \text { Flywheel Energy Storage } \\ \text { HESS } & \text { Hybrid Energy Storage System } \\ \text { IFOC } & \text { Indirect Field Oriented Control } \\ \text { SCADA } & \text { Supervisory Control and Data Acquisition } \\ \text { SOC } & \text { State of Charge } \\ \text { UCES } & \text { Ultracapacitor Energy Storage }\end{array}$

\section{References}

1. Cao, X.; Dai, X.; Liu, J. Building energy-consumption status worldwide and the state-of-the-art technologies for zero-energy buildings during the past decade. Energy Build. 2016, 128, 198-213. [CrossRef]

2. Goudarzi, H.; Mostafaeipour, A. Energy saving evaluation of passive systems for residential buildings in hot and dry regions. Renew. Sustain. Energy Rev. 2017, 68, 432-446. [CrossRef]

3. Huang, H.; Chen, L.; Hu, E. A new model predictive control scheme for energy and cost savings in commercial buildings: An airport terminal building case study. Build. Environ. 2015, 89, 203-216. [CrossRef] 
4. Yoon, J.H.; Bladick, R.; Novoselac, A. Demand response for residential buildings based on dynamic price of electricity. Energy Build. 2014, 80, 531-541. [CrossRef]

5. Alfieri, S.; Piccini, S.; Kermani, M. Feasibility study of Nearly Zero Energy Building in a real Microgrid case study. In Proceedings of the 2019 IEEE International Conference on Environment and Electrical Engineering and 2019 IEEE Industrial and Commercial Power Systems Europe (EEEIC/I\&CPS Europe) IEEE, Genoa, Italy, 11-14 June 2019; pp. 1-6.

6. Kermani, M.; Adelmanesh, B.; Shirdare, E.; Sima, C.A.; Carnì, D.L.; Martirano, L. Intelligent energy management based on SCADA system in a real Microgrid for smart building applications. Renew. Energy 2021, 171, 1115-1127. [CrossRef]

7. Martirano, L.; Rotondo, S.; Kermani, M.; Massarella, F.; Gravina, R. Power Sharing Model for Energy Communities of Buildings. IEEE Trans. Ind. Appl. 2021, 57, 170-178. [CrossRef]

8. Kermani, M.; Carnì, D.L.; Rotondo, S.; Paolillo, A.; Manzo, F.; Martirano, L. A Nearly Zero-Energy Microgrid Testbed Laboratory: Centralized Control Strategy Based on SCADA System. Energies 2020, 13, 2106. [CrossRef]

9. Nipkow, J.; Schalcher, M. Energy consumption and efficiency potentials of lifts. Hospitals 2006, 2, 3.

10. Jabbour, N.; Mademlis, C. Improved Control Strategy of a Supercapacitor-Based Energy Recovery System for Elevator Applications. IEEE Trans. Power Electron. 2016, 31, 1. [CrossRef]

11. Rufer, A.; Barrade, P. A supercapacitor-based energy-storage system for elevators with a soft commutated inter-face. IEEE Trans. Ind. Appl. 2002, 38, 1151-1159. [CrossRef]

12. Kafalis, K.; Karlis, A.D. Comparison of flywheels and supercapacitors for energy saving in elevators. In Proceedings of the 2016 IEEE Industry Applications Society Annual Meeting, IEEE, Portland, OR, USA, 2-6 October 2016; pp. 1-8.

13. Pham, T.H.; Prodan, I.; Genon-Catalot, D.; Lefevre, L. Efficient energy management for an elevator system under a constrained optimization framework. In Proceedings of the 2015 19th International Conference on System Theory, Control and Computing (ICSTCC), Cheile Gradistei, Romania, 14-16 October 2015; pp. 613-618.

14. Liu, H.-P.; Liu, K.; Sun, B.-N. Analysis of energy management strategy for energy-storage type elevator based on supercapacitor. In Proceedings of the 2017 11th IEEE International Conference on Compatibility, Power Electronics and Power Engineering (CPE-POWERENG), Cadiz, Spain, 4-6 April 2017; pp. 175-180.

15. Kubade, P.; Umathe, S.K. Enhancing an elevator efficiency by using supercapacitor. In Proceedings of the 2017 Third Inter-national Conference on Advances in Electrical, Electronics, Information, Communication, and Bio-Informatics (AEEICB), Chennai, India, 27-28 February 2017; pp. 502-505.

16. Jabbour, N.; Mademlis, C. Supercapacitor-Based Energy Recovery System with Improved Power Control and Energy Management for Elevator Applications. IEEE Trans. Power Electron. 2017, 32, 9389-9399. [CrossRef]

17. Ferreira, F.J.; Almeida, A. Reducing Energy Costs in Electric-Motor-Driven Systems: Savings Through Output Power Reduction and Energy Regeneration. IEEE Ind. Appl. Mag. 2017, 24, 84-97. [CrossRef]

18. Zeb, K.; Ali, Z.; Saleem, K.; Uddin, W.; Javed, M.A.; Christofides, N. Indirect field-oriented control of induction motor drive based on adaptive fuzzy logic controller. Electr. Eng. 2016, 99, 803-815. [CrossRef]

19. Kermani, M.; Parise, G.; Martirano, L.; Parise, L.; Chavdarian, B. Power Balancing in STS group Cranes with Flywheel Energy Storage based on DSM Strategy. In Proceedings of the 2018 IEEE 59th International Scientific Conference on Power and Electrical Engineering of Riga Technical University (RTUCON), Riga, Latvia, 12-14 November 2018; pp. 1-5.

20. Kermani, M.; Parise, G.; Martirano, L.; Parise, L.; Chavdarian, B. Optimization of Peak Load Shaving in STS Group Cranes Based on PSO Algorithm. In Proceedings of the 2018 IEEE International Conference on Environment and Electrical Engineering and 2018 IEEE Industrial and Commercial Power Systems Europe (EEEIC/I\&CPS Europe), Palermo, Italy, 11-14 June 2018; pp. 1-5.

21. Uddin, M.; Romlie, M.F.; Abdullah, M.F.; Abd Halim, S.; Kwang, T.C. A review on peak load shaving strategies. Renew. Sustain. Energy Rev. 2018, 82, 3323-3332. [CrossRef]

22. Gür, T.M. Review of electrical energy storage technologies, materials and systems: Challenges and prospects for large-scale grid storage. Energy Environ. Sci. 2018, 11, 2696-2767. [CrossRef]

23. Grbovic, P.J. Ultra-Capacitors in Power Conversion Systems: Applications, Analysis, and Design from Theory to Practice; John Wiley \& Sons: West Sussex, UK, 2013.

24. Arani, A.K.; Karami, H.; Gharehpetian, G.; Hejazi, M. Review of Flywheel Energy Storage Systems structures and applications in power systems and microgrids. Renew. Sustain. Energy Rev. 2017, 69, 9-18. [CrossRef]

25. Divya, K.C.; Østergaard, J. Battery energy storage technology for power systems-An overview. Electr. Power Syst. Res. 2009, 79, 511-520. [CrossRef]

26. Grbovic, P.J.; Delarue, P.; Le Moigne, P.; Bartholomeus, P. The Ultracapacitor-Based Controlled Electric Drives with Braking and Ride-Through Capability: Overview and Analysis. IEEE Trans. Ind. Electron. 2010, 58, 925-936. [CrossRef]

27. Kermani, M.; Parise, G.; Martirano, L.; Parise, L.; Chavdarian, B. Utilization of Regenerative Energy by Ultracapacitor Sizing for Peak Shaving in STS Crane. In Proceedings of the 2019 IEEE International Conference on Environment and Electrical Engineering and 2019 IEEE Industrial and Commercial Power Systems Europe (EEEIC/I\&CPS Europe), Genoa, Italy, 11-14 June 2019; pp. 1-5.

28. Li, T.; Huang, L.; Liu, H. Energy management and economic analysis for a fuel cell supercapacitor excavator. Energy 2019, 172, 840-851. [CrossRef]

29. Sirmelis, U.; Zakis, J.; Grigans, L. Optimal supercapacitor energy storage system sizing for traction substations. In Proceedings of the 2015 IEEE 5th International Conference on Power Engineering, Energy and Electrical Drives (POWERENG), Riga, Latvia, 11-13 May 2015; pp. 592-595. 
30. Fathima, A.H.; Palanisamy, K. Battery energy storage applications in wind integrated systems-a review. In Proceedings of the 2014 International Conference on Smart Electric Grid (ISEG), Guntur, India, 19-20 September 2014; pp. 1-8.

31. Ghorbanzadeh, M.; Astaneh, M.; Golzar, F. Long-term degradation based analysis for lithium-ion batteries in off-grid wind-battery renewable energy systems. Energy 2019, 166, 1194-1206. [CrossRef]

32. Yang, Y.; Bremner, S.; Menictas, C.; Kay, M. Battery energy storage system size determination in renewable energy systems: A review. Renew. Sustain. Energy Rev. 2018, 91, 109-125. [CrossRef]

33. Alsaidan, I.; Khodaei, A.; Gao, W. A Comprehensive Battery Energy Storage Optimal Sizing Model for Microgrid Applications. IEEE Trans. Power Syst. 2018, 33, 3968-3980. [CrossRef]

34. Mohamadi, B.; Noshahr, J.B.; Adelmanesh, B.; Shidare, E.; Kermani, M. Optimal Battery Energy Storage Sizing in Microgrids by using Artificial Flora Algorithm. In Proceedings of the 2020 IEEE International Conference on Environment and Electrical Engineering and 2020 IEEE Industrial and Commercial Power Systems Europe (EEEIC/I\&CPS Europe), Madrid, Spain, 9-12 June 2020; pp. 1-6.

35. Bayati, N.; Baghaee, H.R.; Hajizadeh, A.; Soltani, M. Localized protection of radial DC microgrids with high penetration of constant power loads. IEEE Syst. J. 2020, 1-12. [CrossRef]

36. Theliander, O.; Kersten, A.; Kuder, M.; Han, W.; Grunditz, E.A.; Thiringer, T. Battery Modeling and Parameter Ex-traction for Drive Cycle Loss Evaluation of a Modular Battery System for Vehicles Based on a Cascaded H-Bridge Multilevel Inverter. IEEE Trans. Ind. Appl. 2020, 56, 6968-6977. [CrossRef]

37. Zhang, Y.; Jiang, Z.; Yu, X. Control Strategies for Battery/Supercapacitor Hybrid Energy Storage Systems. In Proceedings of the 2008 IEEE Energy 2030 Conference, Atlanta, Georgia, 17-18 November 2008; pp. 1-6.

38. Oudalov, A.; Cherkaoui, R.; Beguin, A. Sizing and Optimal Operation of Battery Energy Storage System for Peak Shaving Application. In 2007 IEEE Lausanne Power Tech; IEEE: Lausanne, Switzerland, 2007; pp. 621-625.

39. Kermani, M.; Parise, G.; Chavdarian, B.; Martirano, L. Ultracapacitors for port crane applications: Sizing and tech-no-economic analysis. Energies 2020, 13, 2091. [CrossRef]

40. Available online: https://www.byd.com/en/NewEnergy.html (accessed on 20 September 2020).

41. Available online: https:/ / www.maxwell.com/products/ultracapacitors/modules (accessed on 20 June 2020). 